\title{
Mediating role of neuroticism between early maladaptive schemas and negative emotionality
}

\author{
Dorota Macik (D) $1 \cdot A, B, D, E, F$, Matgorzata Eysiak (D) $1 \cdot A, B, D, E, F$, Radostaw Mącik (D) ${ }^{2 \cdot C}$ \\ 1: John Paul II Catholic University of Lublin, Poland \\ 2: Maria Curie-Sklodowska University in Lublin, Poland
}

BACKGROUND

The study contributes to the understanding of the relation between neuroticism, early maladaptive schemas and negative emotionality. Various studies of schemas and neuroticism with the connection of negative emotionality do not give an answer to the question how these three variables co-exist with each other. The main purpose of the research was to determine whether neuroticism strengthens the effect of schemas in the prediction of intensity of anxiety and depression, or whether the roles of these variables are independent of each other.

\section{PARTICIPANTS AND PROCEDURE}

493 healthy participants were included in the study, where $66 \%$ were female respondents and the age range was $16-61$ years of age $(M=31.00, S D=11.96)$. The Young Schema Questionnaire Short Form Version (YSQ-S3), the Revised Personality Inventory (NEO PI-R) by Costa and $\mathrm{McC}$ rae and the Personality Inventory (SPI, TPI by Spielberger \& Reheiser) were used.
RESULTS

The results show a strong relationship between Rejection and Disconnection schemas and negative emotionality, strongly mediated by neuroticism. The trigger for the trait of neuroticism is the intensification of depressive traits, understood as a set of emotional symptoms, i.e. a high level of anxiety, experiencing frequent anger towards oneself, and simultaneously a strong sense of guilt for negative thoughts resulting in a sense of hopelessness.

\section{CONCLUSIONS}

Most of the problems leading to anxiety or depression symptoms originate in schemas of Rejection and Disconnection and neuroticism is a strong mediator for negative emotionality.

\section{KEY WORDS}

neuroticism; early maladaptive schemas; negative emotionality

CORResPonding AUthor - Małgorzata Łysiak, Ph.D., John Paul II Catholic University of Lublin, 14 Racławickie Avenue, 20-950 Lublin, Poland, e-mail: lysiak@kul.pl

AUthors' CONTRIBUtion - A: Study design - B: Data collection - C: Statistical analysis · D: Data interpretation .

E: Manuscript preparation · F: Literature search · G: Funds collection

TO CITE THIS ARTICLE - Mącik, D., Łysiak, M., \& Mącik, R. (2019). Mediating role of neuroticism between early

maladaptive schemas and negative emotionality. Current Issues in Personality Psychology, 7(3), 220-231.

RECEIVED 23.04.2019 · REVIEWED 05.09.2019 • ACCEPTED 13.09.2019 • PUBLISHED 30.09.2019 


\section{BACKGROUND}

According to Beck's theory, the schemas that form the foundation of the quality of human functioning should be treated as filters giving stimuli specific meaning during their processing and coding (Beck et al., 1979). These schemas, also known as core beliefs, are characterized by absolute character and dichotomy. Depending on their content - positive or negative - they give rise to specific conditional assumptions or obligations that allow one to orientate in oneself and in the surrounding reality. These assumptions, called intermediate beliefs, lead to the creation of automatic thoughts, i.e. spontaneous thoughts, images or memories (Padesky \& Greenberger, 1995). Thoughts with underlying negative patterns are the cause of negative emotional states, usually of anxious or depressive character.

Jeffrey Young, building on Beck's theory and the achievements of cognitive-behavioural therapy, focused on negative beliefs. He credited parental attitudes with playing an important role in the genesis of negative beliefs, especially if they are reinforced by an emotional temperament (Young, Klosko, \& Weishaar, 2003). He also accepted that the basic structure and the emotional climate of these assumptions are formed in early childhood and in later stages of life undergo continuous strengthening. Since these schemas are negative beliefs about themselves and the world, the intermediate beliefs and automatic thoughts generated by them are characterized by negative emotionality. The most common emotions associated with the schemas are anxiety, depression and anger.

The existing literature provides a lot of data indicating the relationship of schemas with depressive disorders and anxiety. Hankin, Abramson, Miller, and Haeffel (2004) pointed to the role of cognitive vulnerability in predicting depression. In studies by Calvete, Orue, and González-Diez (2013), the schemas explained $36 \%$ of symptoms of depression and $22 \%$ of anxiety. Symptoms of depression were primarily related to the schemas of Disconnection, whereas social anxiety was primarily related to the search for acceptance and emotional inhibition. Camara and Calvete (2012) indicated that the schemas lead to experiencing distress, while the experience of its intensity is mediated by coping strategies. In studies among adolescents, it was also confirmed that early maladaptive schema (EMS) are strongly correlated with symptoms of depression and anxiety, while in the case of men, an important role in predicting depression was observed in schemas within the domains of Disconnection/Rejection and OtherDirectedness (Calvete, Orue, \& Hankin, 2015). These studies, as well as some others, give different results about the role of specific schemas of experiencing emotions, depending on the group, age or type of psychopathology. However, all of them pointed to the Disconnection/Rejection domain as the most important in the case of both depression and anxiety.

Anxiety and depression are emotions that often coexist. Depressive beliefs forming the so-called Beck's triad regarding negative views about oneself, the world and the future contain a strong anxiety component related to the fear of further effective functioning. In turn, the emotion of anxiety, which is dominant in anxiety disorders, is a reaction to the conviction of a threatening world and lack of faith in one's competences. However, the emergence of a vicious cycle of anxiety leads to increased feelings of helplessness and inadequacy, activating negative, depressive beliefs (Wells, 1997). Both emotions co-exist in experiencing difficult situations, which is reflected in numerous publications analysing their intensity in various specific contexts (see e.g.: Açmaz et al., 2013; Cinar et al., 2011; Clark \& Steer, 1996; Krepula, Bidzinska-Speichert, Lenarcik, \& Tworowska-Bardzinska, 2012; Stefanaki et al., 2014). Also in adaptive studies of the method, the EMS compounds were demonstrated several times to be related to anxiety and depression (e.g. Oettingen, Chodkiewicz, Mącik, \& Gruszczyńska, 2017). The second trend of research highlights the important role of neuroticism in generating negative emotions. A wide review of previous research on the role of personality is presented by Weinstock and Whisman (2006). They point to numerous documented studies in which neuroticism is an important feature in terms of emotional regulation and the severity of both anxiety and depression, in clinical as well as non-clinical groups. At the same time, their own results conducted on a very large group indicate that participants with both anxiety and depression as well as those with both types of disorders are characterized by a significantly higher level of neuroticism compared to the control group. In the case of pure disorders (anxiety and depression) the level of neuroticism was the same, while their cooccurrence was associated with a significantly higher level of neuroticism. The interesting thing is that neuroticism is higher in the case of generalized anxiety than in phobias, panic and post-traumatic stress disorder (PTSD). In the case of depression, those with dysthymia had a level of neuroticism similar to the control group. They emphasize the fact that research conducted in the non-clinical population strengthens the significance of the presented correlations.

Numerous studies of schemas as well as neuroticism with the connection with negative emotionality do not give an answer to the question how these three variables co-exist with each other. The question arises whether neuroticism strengthens the effect of schemas in the prediction of intensity of anxiety and depression, or whether the role of these variables is independent of each other.

According to Young, the schemas are stronger if superimposed on a more emotional type of tempera- 
ment. Thimm (2010) points to strong correlations of schemas with the dimensions of the Big Five, especially with neuroticism. In turn, in studies by Calvete (2014), neuroticism was a predictor of more severe patterns in the case of experiencing mental violence. Similarly, Mairet, Boag, and Warburton (2014) indicate the role of neuroticism, especially strong in relation to the domain of Disconnection/ Rejection. Arthurs and Tan (2017) studied people with a history of non-suicidal self-injury who were characterized by a significantly higher intensity of both schemas and the level of neuroticism than the control group. Based on these and similar studies, it can be assumed that if it is possible to observe mutual relations between schemas and neuroticism, and between schemas and emotions, there is probably also a significant relationship between all variables at the same time.

So the question was posed - is there a relationship, and if so, what kind, between schemas and neuroticism and anxiety and depression? Thus, the following hypotheses were put forward:

1a. Early maladaptive schemas from different domains will significantly explain the intensity of anxiety.

1b. When explaining anxiety, the Disconnection/ Rejection and Other-Directedness domains will have the biggest contribution.

2a. Early maladaptive schemas from different domains will significantly explain the intensity of depression.

2b. When explaining depression, the Disconnection/ Rejection domain will have the biggest contribution.

3. Neuroticism will significantly increase the amount. of the explained variable of the intensity of emotion.

4. Neuroticism will act as a mediator between schemas and emotions (based on conclusions by Weinstock \& Whisman, 2006).

\section{PARTICIPANTS AND PROCEDURE}

\section{PARTICIPANTS}

In order to verify the hypotheses, 500 people were examined, and 493 questionnaires were accepted for the analysis. Only healthy people were included in the study. Obtaining any information on the presence of current or past mental illness or the use of psychiatric treatment or psychotherapy was the grounds for exclusion from the study. Due to aiming at measuring the state of anxiety and depression independent of the current life situation that could justify increased anxiety, the study excluded people with serious somatic illness, either their own or that of their close relatives, one year after a divorce and after a loss (death) of a close relative. All data, including personal data, have been collected in accordance with standards of research in psychology.
The respondents were between 16 and 61 years of age, on average 31 years old ( $S D-11.96$ years). There were more female respondents (66\% vs. $34 \%$ ). The vast majority of respondents come from a complete family $(87 \%), 2 \%$ from reconstructed families, and slightly more than $10 \%$ from incomplete families. About $92 \%$ define themselves as religious persons. Most of the respondents live in large cities and rural areas (respectively 36\% and 26\%), slightly less in average and small cities (19\% and $15 \%)$. They rate their financial status as average and good (46\% and $43 \%$ ), only a few as bad (less than $4 \%$ ) or very good (just over 6\%). Most of the respondents are in relationships, both formal and unregistered (30\% and $27 \%$ respectively) and work in their profession (66\%).

\section{MEASURES AND PROCEDURE}

The following methods were used to verify the hypotheses:

1. Early maladaptive schemas. Young Schema Questionnaire Short Form Version (YSQ-S3) consists of 90 statements that refer to the beliefs that the participant has about themselves, the world and relationships with others. The examined person reacts to each of the items on the scale $1-6$, where 1 means completely untrue of me, and 6 means describes me perfectly. The higher the test results obtained by the participant, the more rigid the schemas are. The questionnaire diagnoses the intensity of 18 schemas, which make up five general domains: Disconnection and Rejection (Abandonment/Instability, Mistrust/Abuse, Emotional Deprivation, Defectiveness/Shame, Social Isolation/Alienation), Impaired Autonomy and Performance (Dependence/Incompetence, Vulnerability to Harm/Illness, Enmeshment/Undeveloped Self, Failure), Impaired Limits (Entitlement/Grandiosity, Insufficient Self-control/ Self-discipline), Other-Directedness (Subjugation, Self-Sacrifice, Approval Seeking/Recognition-Seeking), Overvigilance and Inhibition (Negativity/Pessimism, Emotional Inhibition, Unrelenting Standards/Hypercriticalness, Punitiveness). The Polish version of the questionnaire was developed in 2017 (Oettingen et al., 2018). It does not differ from other language versions, both in terms of strengths and weaknesses, and the measurement is characterized by relatively high, acceptable reliability.

2. Personality traits. The Revised Personality Inventory (NEO PI-R) by Costa and McCrae in the Polish adaptation of Siuta $(2006,2009)$ is the operationalization of a five-factor personality model that describes the basic dimensions of personality. The inventory consists of 240 statements answered by an examined person on a five-point scale: strongly disagree, disagree, neither agree nor disagree, agree, strongly agree. The raw results obtained are con- 
verted into the sten scale $(M=5.50, S D=2.00)$, and the norms are adapted respectively for women and for men. The NEO PI-R Inventory consists of the following factors: Neuroticism $(\mathrm{N})$, Extraversion (E), Openness to Experience (O), Agreeableness (A) and Conscientiousness (C); each of these has six sub-scales. The reliability of the scales in the standardization study turned out to be sufficiently high; the lowest Cronbach $\alpha$ coefficient was obtained for the Agreeableness factor $(\alpha=.81)$, and for the remaining factors the coefficients were very similar (.85-.86). For the purpose of the study, only the neuroticism factor was used.

3. Affective states/traits. The Personality Inventory by Spielberger to measure affective states and traits (SPI and TPI). The method by Spielberger and Reheiser (2003) to measure affective states (SPI) and affective traits (TPI) assesses anxiety, anger, curiosity, and depression. Each questionnaire consists of 40 statements making up four 10-item subscales. The SPI Inventory assesses the subject's current emotional state, and the TPI Inventory assesses an emotion understood more as a trait. The respondent's answers are rated on a four-point scale, and the result is the sum of points in individual scales. The Polish version of the method developed by Oleś and Wrześniewski (see: Oleś, Brygoła, \& Sibińska, 2010 , p. 25) was used in the research, where the re- liability measured by the Cronbach $\alpha$ coefficient is, respectively, for the following scales: anxiety -.75 ; anger - .68; depression - .85; and curiosity - .75 (Spielberger \& Reheiser, 2009). To verify the hypotheses, the Anxiety and Depression scales were used, both in the state and trait dimensions.

The reliability of measurements (Cronbach's $\alpha$ and composite reliability - CR) and indicators for convergent validity (average variance extracted - AVE) and discriminant validity (based on Fornell-Larcker criterion) for constructs used in models (Anxiety, Depression, Neuroticism, Rejection domain) are presented in Table 1.

All reliability measures, as well as the convergent reliability indicator AVE, are higher than the required threshold, i.e. of .70 for Cronbach's $\alpha$ and CR measure and .50 for AVE, indicating good reliability and convergent validity. Discriminant validity analysis suggests on the basis of the Fornell-Larcker criterion meeting the requirements of adequate discriminant validity, as for all constructs their square roots from AVEs are higher than any correlation between the analysed construct and other latent variables in the models.

In statistical analyses, the covariance-based structural equation modelling (CB-SEM) approach was used, making calculations in the IBM AMOS 24 statistical package.

Table 1

Reliability and validity coefficients for constructs used in models

\begin{tabular}{|c|c|c|c|c|c|c|}
\hline \multirow[t]{2}{*}{ Constructs } & \multicolumn{2}{|c|}{ Construct reliability } & \multirow{2}{*}{$\begin{array}{c}\begin{array}{c}\text { Construct } \\
\text { validity }\end{array} \\
\text { AVE }\end{array}$} & \multicolumn{3}{|c|}{$\begin{array}{c}\text { Discriminant validity } \\
\text { (Fornell-Larcker criterion) }\end{array}$} \\
\hline & Cronbach's $\alpha$ & CR & & (1) & $(2)$ & (3) \\
\hline \multicolumn{7}{|l|}{ Models $1 \mathrm{a}$ and $1 \mathrm{~b}$} \\
\hline Neuroticism (1) & .85 & 0.85 & 0.55 & 0.74 & & \\
\hline Rejection (2) & .90 & 0.89 & 0.63 & 0.58 & 0.79 & \\
\hline Depression (3) & .84 & 0.85 & 0.74 & 0.71 & 0.69 & 0.86 \\
\hline \multicolumn{7}{|l|}{ Models $2 \mathrm{a}$ and $2 \mathrm{~b}$} \\
\hline Neuroticism (1) & .85 & 0.86 & 0.56 & 0.75 & & \\
\hline Rejection (2) & .90 & 0.89 & 0.63 & 0.59 & 0.79 & \\
\hline Anxiety (3) & .74 & 0.79 & 0.66 & 0.78 & 0.68 & 0.81 \\
\hline \multicolumn{7}{|l|}{ Models 3 and $3 b$} \\
\hline Neuroticism (1) & .85 & 0.87 & 0.57 & 0.76 & & \\
\hline Rejection (2) & .90 & 0.89 & 0.63 & 0.59 & 0.79 & \\
\hline $\begin{array}{l}\text { Negative } \\
\text { emotionality (3) }\end{array}$ & .91 & 0.90 & 0.69 & 0.77 & 0.69 & 0.83 \\
\hline
\end{tabular}

Note. CR - composite reliability; AVE - average variance extracted. On diagonal - square root from AVE, below diagonal - correlations between constructs. Fornell-Larcker criterion is met when square root from AVE is higher than any correlation in corresponding column or row. 


\section{RESULTS}

The statistical analyses undertaken were aimed at determining which domains of schemas explain anxiety and depression and how they do so. The following explained variables were taken: 1) anxiety, 2) depression; in both cases, the descriptors were the state and trait measured by Spielberger's SPI and TPI, respectively. Two groups of factors were assumed as explanatory variables. The first of them was the five domains of schemas described by their respective dimensions. It was assumed that they will directly affect the level of emotions. The second explanatory variable was neuroticism (measured by NEO PI-R), assuming, based on other calculations and previous studies, that it will be definitely the most vital for explaining the intensity of emotions. Two model systems were tested: in the first one, only the dependency between schemas and the intensity of anxiety and depression were examined, while in the second the feature of neuroticism was added, giving it a mediating character.

In the first stage of the analysis, all domains of schemas as variables explaining depression were included in the model; the procedure was also repeated for anxiety. In both cases, only the Dependence of Re- jection domain was relevant. The final models of this stage of analyses are presented in Figures 1 and 2, and the fit indices for all models are presented in Table 2. Models $1 \mathrm{a}$ and $1 \mathrm{~b}$ explain depression, models $2 \mathrm{a}$ and $2 \mathrm{~b}$ explain anxiety, while $3 \mathrm{a}$ and $3 \mathrm{~b}$ show negative emotionality. The letter 'a' indicates a model built solely on the basis of schemas, and ' $b$ ' indicates a model with the feature of neuroticism as a mediator.

In the case of model 1a (Figure 1) explaining depression, the standardized path coefficient is .68 $(p<.001)$ and alone explains $46 \%$ of the variability with very good fit indices. These values are similar in the case of anxiety (model 2a, Figure 1). It is worth noting that the adjustment to the data is even better, while the value of the explained variable reaches $49 \%$ with the value of the standardized path coefficient .70. These data clearly indicate the importance of schemas for explaining the intensity of negative emotions. At the same time, none of the schematic domains, apart from the Rejection/Disconnection schema, obtained a significant path factor, which indicates a more important role for this domain. This means that the intensity of both anxiety and depression (understood as a state and a trait) is significantly correlated with five schemas, indicating an unsatisfied need for acceptance.
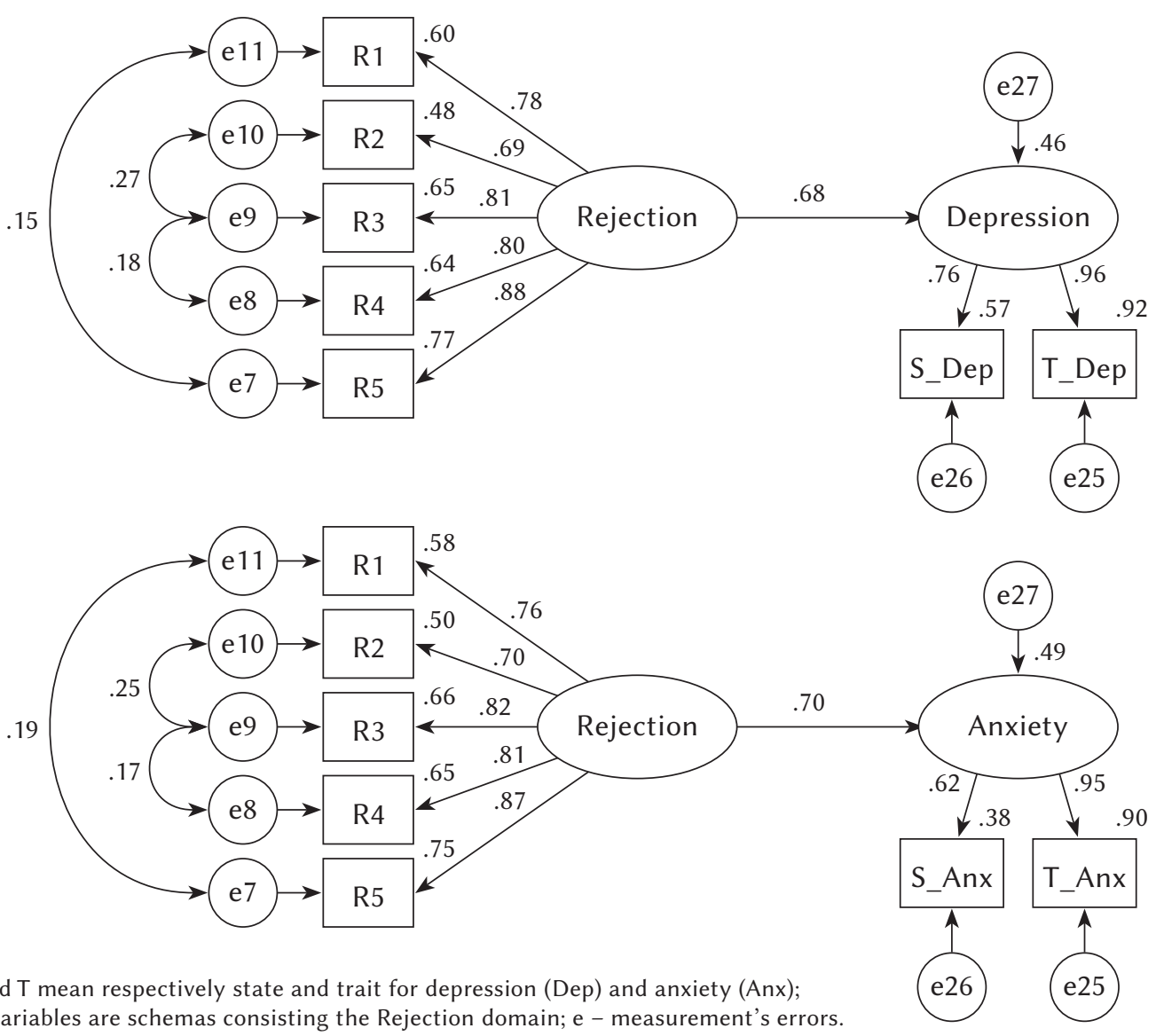

Note. S and T mean respectively state and trait for depression (Dep) and anxiety (Anx)

$\mathrm{R} 1$ to R5 variables are schemas consisting the Rejection domain; e - measurement's errors

Figure 1. Models 1a (above) and 2a (below). 


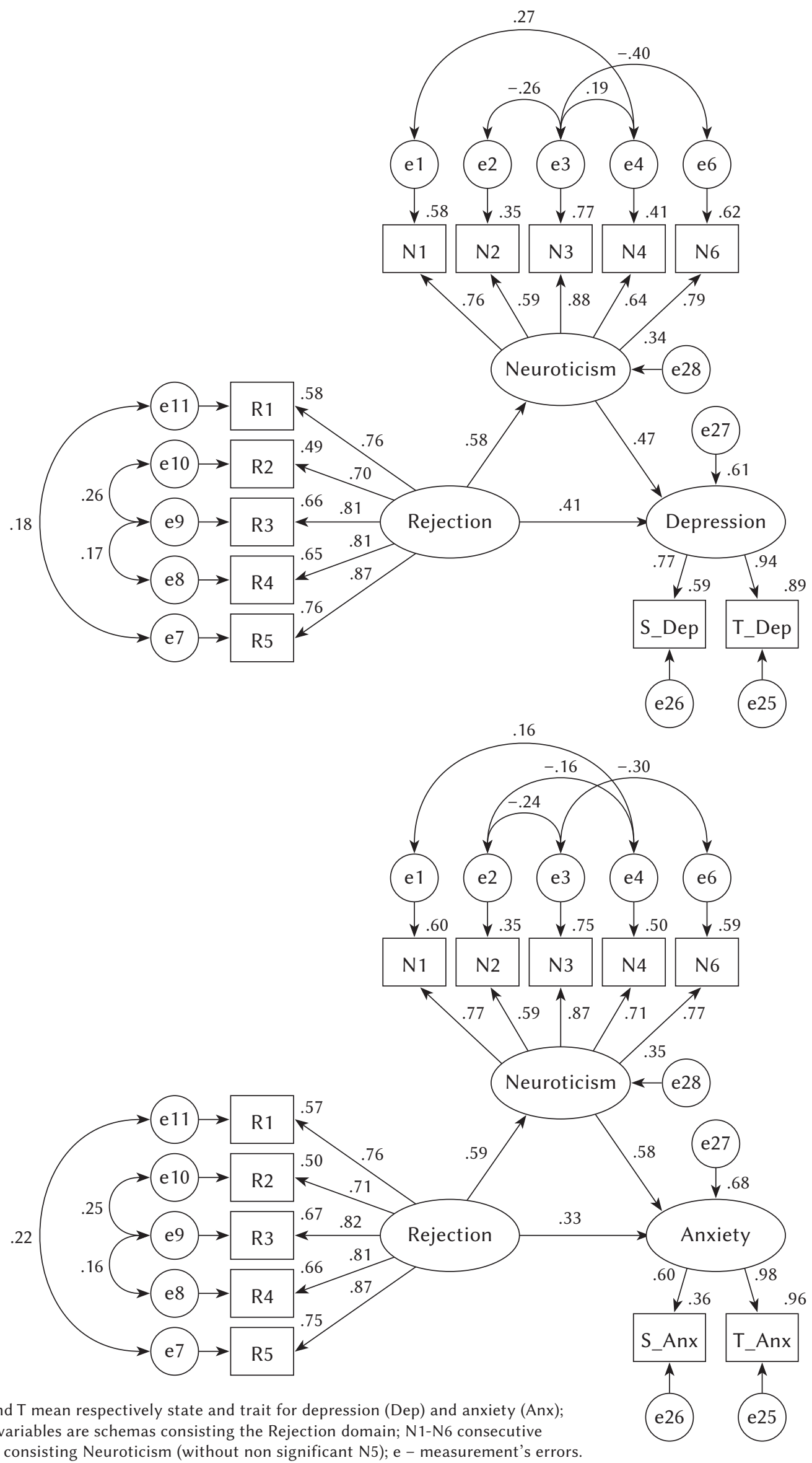

R1 to R5 variables are schemas consisting the Rejection domain; N1-N6 consecutive

subscales consisting Neuroticism (without non significant N5); e - measurement's errors.

Figure 2. Models $1 \mathrm{~b}$ (above) and $2 \mathrm{~b}$ (below). 
Table 2

Fit indices for models explaining depression (1), anxiety (2) and negative emotionality (3)

\begin{tabular}{|c|c|c|c|c|c|c|c|}
\hline \multirow{2}{*}{$\begin{array}{l}\text { Fit } \\
\text { Indices }\end{array}$} & \multirow{2}{*}{$\begin{array}{l}\text { Reference } \\
\text { values* }\end{array}$} & \multicolumn{6}{|c|}{ Models } \\
\hline & & $1 \mathrm{a}$ & $1 b$ & $2 a$ & $2 b$ & $3 a$ & $3 b$ \\
\hline$\chi^{2}(d f)$ & - & $10.28(10)$ & $134.96(44)$ & $17.88(10)$ & $132.05(44)$ & $41.67(22)$ & $177.17(63)$ \\
\hline$p\left(\chi^{2}\right)$ & $>.05$ (n.s.) & .417 & $<.001$ & .057 & $<.001$ & .007 & $<.001$ \\
\hline$\chi^{2} / d f$ & $<2$ or 3 & 1.027 & 3.067 & 1.788 & 3.001 & 1.894 & 2.812 \\
\hline GFI & $>0.95$ & 0.994 & 0.959 & 0.990 & 0.959 & 0.982 & 0.950 \\
\hline AGFI & $>0.80$ & 0.984 & 0.927 & 0.973 & 0.927 & 0.963 & 0.916 \\
\hline NFI & $>0.90$ & 0.995 & 0.963 & 0.991 & 0.964 & 0.988 & 0.965 \\
\hline TLI & $>0.95$ & 1.000 & 0.962 & 0.992 & 0.963 & 0.991 & 0.967 \\
\hline CFI & $>0.95$ & 1.000 & 0.975 & 0.996 & 0.975 & 0.994 & 0.977 \\
\hline RMSEA & $\begin{array}{l}<0.05 \\
<0.07\end{array}$ & 0.007 & 0.064 & 0.039 & 0.063 & 0.042 & 0.060 \\
\hline$(90 \% \mathrm{Cl})$ & - & $0.000-0.049$ & $0.052-0.076$ & $0.000-0.068$ & $0.051-0.075$ & $0.022-0.061$ & $0.049-0.070$ \\
\hline PCLOSE & $>0.05$ (n.s.) & 0.956 & 0.032 & 0.692 & 0.043 & 0.734 & 0.060 \\
\hline$R^{2}$ & - & .46 & .62 & .49 & .68 & .50 & .68 \\
\hline
\end{tabular}

Note. $R^{2}$ for explained variable. Abbreviations: GFI - goodness of fit index, AGFI - adjusted goodness of fit index, NFI - normed-fit index, TLI - Tucker-Lewis index, CFI - comparative fit index, RMSEA - root mean square error of approximation, PCLOSE - probability of close fit. *by: Iacobucci (2010)

In the next stage, it was decided to include the trait of neuroticism, which was understood as a mediator between beliefs constructing schemas and emotions. The resulting two more models are illustrated in Figures 2 and 3, and fit indices in Table 2.

Model 1b explains about $15 \%$ more of depression variability than $1 \mathrm{a}$ ( $61 \%$ and $46 \%$ respectively). In the case of mediation, the direct effect of the schemas is weaker $(\beta=.41)$. Stronger effects are observed in relation to the influence of schemas on neuroticism $(\beta=.58)$ and neuroticism on depression $(\beta=.47)$. This means that neuroticism plays a significant role in increasing depression, strengthening the influence of schemas and significantly increasing the amount of explained variables. We observe similar relations in the case of anxiety (model 2b, Figure 2). Also in this case, the strength of the direct effect of schemas on anxiety is reduced, replaced with the intensification of neuroticism, which in return is connected with the higher level of anxiety. As a result, these two variables explain nearly $70 \%$ of the anxiety variability $\left(R^{2}=.68\right)$, with good fit of the models to the data (Table 2).

This stage of analysis clearly indicates that while the schemas themselves are important for explaining the intensity of anxiety and depression, with the neurotic trait they seem to exert a significant influence on the intensity of these emotions. Simultaneously, it is characteristic that in the case of both emotions, the dependencies obtained are almost the same, both in terms of directions as well as the strength of direct and indirect influence. This may indicate the fact that both of these emotions are close enough to each other and perhaps related in everyday experiences that the variables used in the models explain them in the same way and according to similar mechanisms, which would be in line with both Beck's and Young's theories. Therefore, it was decided to verify this assumption by performing analogous analyses, but negative emotionality (understood as one's tendency to experience both depression and anxiety) became the dependent variable, the descriptors of which were the state and trait of anxiety and the state and trait of depression.

Obtained models $3 \mathrm{a}$ and $3 \mathrm{~b}$ (see Figure 3) are also characterized by good fit indices (see Table 2), where model 3a has slightly weaker fit indices to data compared to analogous models, separate for anxiety and depression, while model $3 \mathrm{~b}$ (with neuroticism) has slightly better fit indices. This indicates that the inclusion of such schemas as neuroticism not only significantly increases the amount of the explained variables in terms of emotions, but also better reflects the actual dependencies between variables. Schemas alone explain $50 \%$ of the variability of negative emotionality, with a standardized path factor of $\beta=.70$, which reflects the great power of correlation. After adding neuroticism to the model, we again observe the effect of partial mediation: the standardized 

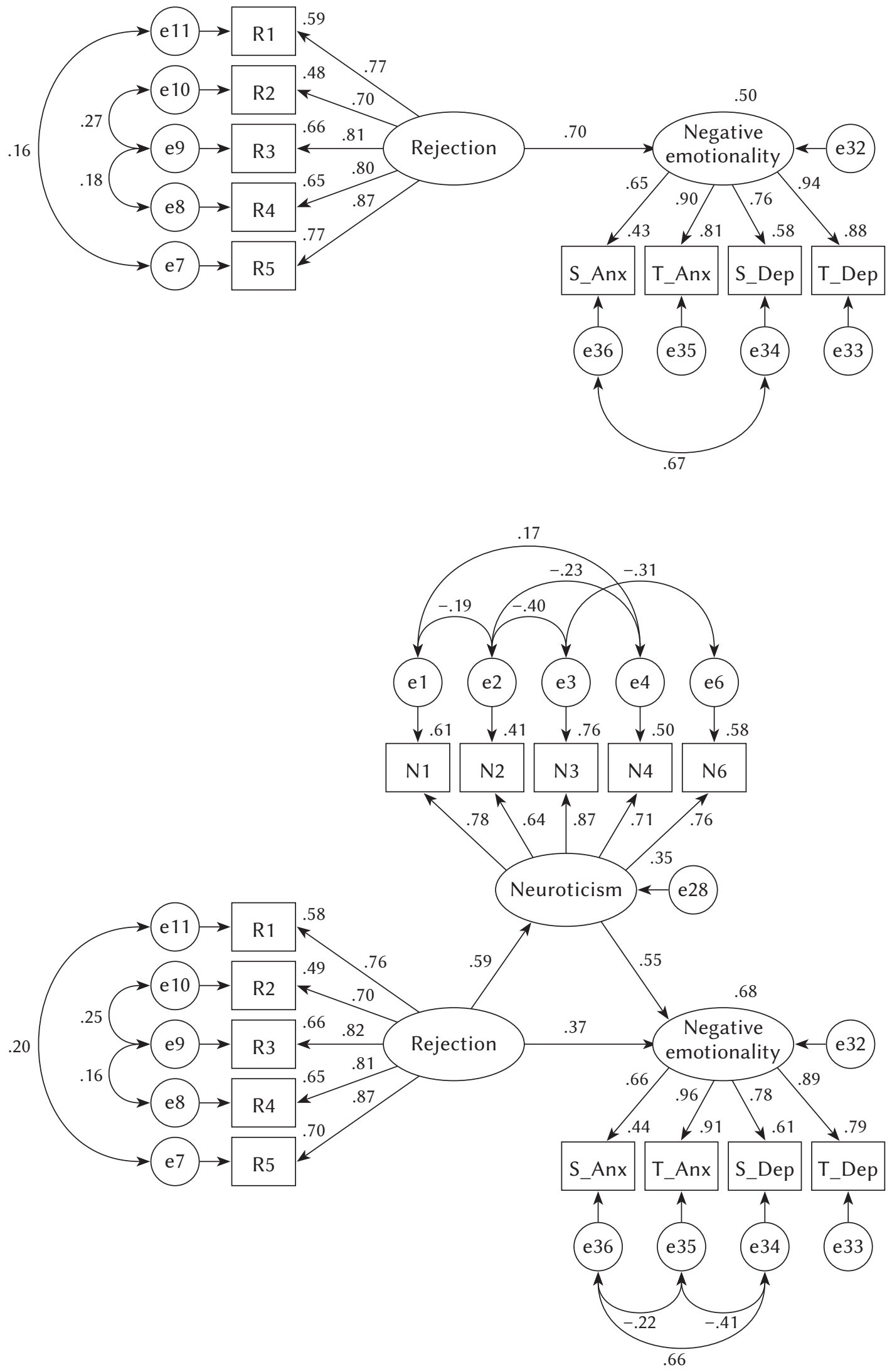

Note. Abbreviations as in Figure 2.

Figure 3. Models 3a (above) and 3b (below) explaining negative emotionality. 
path factor from schemas to emotionality becomes weaker, but there is a strong connection of schemas with neuroticism and neuroticism with emotions (see model 3b, Figure 3); in each case these coefficients are significant at the level of $p<.001$.

The above analysis suggests that it makes sense to interpret anxiety and depression as a common construct. Schemas, and in fact only the Rejection domain, explain about $50 \%$ of the variability of both anxiety and depression as well as both constructs altogether. When the explanation is enriched with the trait of neuroticism, the amount of explained variable increases to about $70 \%$. In each case, models are characterized by a good fit to the data. Another conclusion indicates the important role of schemas, in terms of their direct role as well as in intensifying and possibly activating the neurotic personality traits, which further strengthen the tendency to experience negative emotions.

\section{DISCUSSION}

According to Young, schema therapy is the right tool for treating not only disorders from so-called Axis II, but also those from Axis I (according to DSM-IV-TR), having their source in personality problems (Young et al., 2003), especially those characterized by chronicity or recurrence. This means that personality problems can and should be treated as the actual cause of the appearance of symptoms such as depressed mood, anxiety withdrawal, addictions, etc. Underlying beliefs of the schemas are characterized by a negative emotional climate, connected with lack of fulfilment and frustration of basic emotional needs. Any situation that can potentially trigger a schema, and thus activate emotions, is considered potentially dangerous. Thus, a schema leads to behaviour preventing the activation of emotions (Young et al., 2003).

Despite experiencing suffering resulting from the schema, people tend to repeat it because of the pursuit of stability; however, it causes constant anxiety and the depressed mood associated with it.

The analyses presented above confirm this conclusion. Schemas alone explain about half of the variabilities of anxiety and depression. Such a high value in the study of people from the non-clinical population is worth emphasizing, because it indicates the important role of schemas. The initially accepted assumption that the schemas from different domains will have their share in the genesis of anxiety intensification has not been confirmed (rejection of hypothesis 1a). It turns out that only the domain of Disconnection/Rejection has a significant path factor (model 1a, 1b) - hypothesis 1b has, therefore, been partially confirmed. Schemas from this domain are created due to failure to meet the need for security and acceptance, forming beliefs focused around re- jection and lack of relationship. This rejection may be due to others (schemas: mistrust, abandonment, emotional deprivation) and oneself (defectiveness, social undesirability). A person deprived of a relationship or focused on the expectation of negative effects of relationships cannot create a secure connection to others, and instead of feeling secure, anxiety arises. Anxiety is usually defined as an emotional reaction manifested by tension, nervousness in response to an actually occurring threat or the requirements of the environment interpreted by a person as threatening. The emerging anxiety is accompanied by activation of the autonomic nervous system. It is usually considered as a personality trait or current, temporary state of a person. By the trait of anxiety we mean a relatively constant tendency to an anxious response to a wide range of situations perceived as dangerous, while the state of anxiety refers to the perception of unpleasant emotions (Spielberger \& Reheiser, 2009). The trait of anxiety has a much stronger relationship to general anxiety than the state; it also has stronger factor loadings (see model 2a), and the level of general anxiety increases when schemas from the Disconnection and Rejection domain are activated. Because the patterns are formed earlier than the personality structure, it can be assumed that the continuous absence or deficiency in the level of the satisfaction of need for security and acceptance shapes the trait of anxiety. The schemas' connection with anxiety is weaker if neuroticism, which is a relatively permanent disposition to experience "negative" emotional states, i.e. anxiety, fear, anger and guilt, becomes the mediator (see model 2b, 3b). In the concept of Costa and McCrae, neuroticism includes six components: anxiety, aggressive hostility, depression, impulsiveness, hypersensitivity and excessive self-criticism (Zawadzki, Strelau, Szczepaniak \& Śliwińska, 1998). People who achieve high scores on the neurotic scale are people who are more often less able to control their urges, cope less with stress, and react with strong anxiety or tension in difficult situations. The latter, such as situations of rejection, insecurity, or difficulties in building trust, are characteristic of the schemas in the Disconnection and Rejection domain. These in turn are associated with the development of neurotic behaviour, and in adulthood probably strengthen, and perhaps activate the neurotic personality traits that directly intensify the trait of anxiety. These results are consistent with the research by Bahramizadeh and Ehsan (2011), where the researchers explain that these contents and the early experiences that generate schemas from the Abandonment and Instability domain can be considered as the roots of the development of high neuroticism and an explanation of why neurotic people have a negative perspective about themselves and others, paying no attention to external reality and judging the world as uncertain. The role of neuroticism as a mediator seems justified. 
It is interesting that almost identical relations are observed for depression. Only the schemas from the Disconnection/Rejection domain are relevant here as well, and they work just as strongly here, explaining a similar percentage of variables - rejecting hypothesis $2 \mathrm{a}$ and confirming $2 \mathrm{~b}$. According to Young et al. (2003), this group of schemas causes the most damage in functioning. People often experience a sense of loneliness, lack of love or helplessness, which inevitably affects their thinking about themselves, the world or others. Cognitively, they can generate beliefs from Beck's depressive triad, which is closely related to low self-esteem and depressed mood. Similarly as in anxiety, the mediator of the strong connection of schemas with negative emotionality is neuroticism (see model $1 \mathrm{~b}, 2 \mathrm{~b}$ ) - confirming hypotheses 3 and 4 . People who achieve high scores on the neurotic scale are less likely to be able to control their drives, as well as quickly get discouraged or depressed, and thus a sense of failure affects their low self-esteem, shyness or a sense of confusion in the company of others. The trigger for the trait of neuroticism is the intensification of depressive traits, understood as a set of emotional symptoms, i.e. a high level of anxiety, experiencing frequent anger towards oneself, and simultaneously a strong sense of guilt for negative thoughts resulting in a sense of hopelessness.

There is a powerful relationship between Rejection and Disconnection schemas and negative emotions (called negative emotionality), strongly mediated by neuroticism (this confirms hypothesis 4). This leads to the conclusion that the majority of problems leading to the induction of anxiety or depression symptoms originate in one group of schemas. This means that for the good functioning of a person, relationships based on security are important. Young's theory was strongly influenced by the attachment theory by Bowlby and Ainsworth (1991), whose main assumption is connected with the attachment instinct. A stable attachment to the mother is the source of future independence and autonomy. The effect of a disturbed bond can be both anxiety and building a model of non-valuable Self. In the theory of schemas, the assumption of emotional development is also related to the transition from attachment to individuation, and the element of assimilation and accommodation is still included in this process - that is, keeping the balance between what is new and what is known. People under the influence of schemas misinterpret new information and instead of correcting it through the process of assimilation, individuals distort it so that the patterns can remain intact, which results in an increase in experiencing negative feelings (not necessarily consciously). Perhaps this is because, at the start of the schema most connected to the attachment, it intensifies the trigger of neurotic behaviours, which may be an impediment to the assimilation of new information. This result suggests two conclusions. The first refers to the control of neuroticism as a variable intensifying the occurrence of anxiety and depression. The second one coincides with the conclusion from Thimm's research (2010) that, although work techniques with schemas are available, there are still no specific therapeutic interventions for specific personality traits (including high neuroticism).

\section{CONCLUSIONS}

In conclusion, it should be emphasized that the role of schemas, and especially from the Disconnection/ Rejection domain, is vital for understanding the genesis of anxiety such as depression. The reasoning presented also justifies the sense of joint treatment of both these emotions. This is often practiced both in scientific research and in therapeutic practice, where the coexistence of both emotions is observed. Considering that only one of the schema domains explains half of the variables in terms of emotions, the role of non-adaptive beliefs about oneself cannot be omitted when working with emotions.

Secondly, the presented studies refer to the population of people without disorders. It can be assumed that if the schemas of a relatively low intensity are so vital for negative emotions, this relationship in the case of disorders should be even stronger. This is the starting point for further research. The research is cross-sectional and thus, while the results are consistent with a causal model, they cannot be viewed as definitive proof of causation. A longitudinal study would support the causal model more definitely.

An important limitation of these studies is the fact that the emotional state of participants during the study was not assessed in any way (e.g. sadness or anxiety associated with the current life situation of the participants), which definitely needs to be taken into account in subsequent studies. However, the large number of participants compensates for this absence in some way. The conclusion would also be stronger if people who struggled with anxiety or sadness (in the area of the norm) were to be examined simultaneously and the intensity of dependencies in such controlled groups compared.

Regardless of the aforementioned limitations, it seems that the obtained relationships can be a valuable clue for theoreticians in the aspect of verification of Young's theory as well as for practitioners, expanding the understanding of the persistence of a depressed mood despite therapy.

\section{References}

Açmaz, G., Albayrak, E., Acmaz, B., Başer, M., Soyak, M., Zararsız, G., \& IpekMüderris, I. (2013). Level of 
anxiety, depression, self-esteem, social anxiety, and quality of life among the women with polycystic ovary syndrome. The Scientific World Journal, 2013, 1-7. https://doi.org/10.1155/2013/851815

Ainsworth, M. S., \& Bowlby, J. (1991). An ethological approach to personality development. American Psychologist, 46, 333-341. https://doi.org/10.1037/0003066X.46.4.333

Arthurs, S. D., \& Tan, J. C. H. (2017). Personality traits, early maladaptive schemas, and severity of nonsuicidal self-injury. Psi Chi Journal of Psychological Research, 22, 181-192. https://doi.org/10.24839/23257342.JN22.3.181

Bahramizadeh, H., \& Ehsan, H. B. (2011). The Evaluation of prediction potential neuroticism and extraversion according to early maladaptive schemas. Procedia - Social and Behavioral Sciences, 30, 524529. https://doi.org/10.1016/j.sbspro.2011.10.102

Beck, A. T., Rush, A., Shaw, B., \& Emery, G. (1979). Cognitive therapy of depression. New York, NY: Guilford Press.

Calvete, E. (2014). Emotional abuse as a predictor of early maladaptive schemas in adolescents: Contributions to the development of depressive and social anxiety symptoms. Child Abuse \& Neglect, 38, 735746. https://doi.org/10.1016/j.chiabu.2013.10.014

Calvete, E., Orue, I., \& González-Diez, Z. (2013). An examination of the structure and stability of early maladaptive schemas by means of the Young Schema Questionnaire-3. European Journal of Psychological Assessment, 29, 283-290. https://doi.org/10. 1027/1015-5759/a000158

Calvete, E., Orue, I., \& Hankin, B. L. (2015). A longitudinal test of the vulnerability-stress model with early maladaptive schemas for depressive and social anxiety symptoms in adolescents. Journal of Psychopathology and Behavioral Assessment, 37, 85-99. https://doi.org/10.1007/s10862-014-9438-x

Camara, M., \& Calvete, E. (2012). Cognitive schemas predicting anxiety and depressive symptoms: the role of dysfunctional coping strategies. European Psychiatry, 27, 1. https://doi.org/10.1016/S09249338(12)74289-X

Cinar, N., Kizilarslanoglu, M. C., Harmanci, A., Aksoy, D. Y., Bozdag, G., Demir, B., \& Yildiz, B. O. (2011). Depression, anxiety and cardiometabolic risk in polycystic ovary syndrome. Human Reproduction, 26, 3339-3345. https://doi.org/10.1093/ humrep/der338

Clark, D. A., \& Steer, R. A. (1996). Empirical status of the cognitive model of anxiety and depression. In P. M. Salkovskis \& P. M. (Eds.), Frontiers of cognitive therapy (pp. 75-96). New York, NY: Guilford Press.

Hankin, B. L., Abramson, L. Y., Miller, N., \& Haeffel, G. J. (2004). Cognitive vulnerability-stress theories of depression: examining affective specificity in the prediction of depression versus anxiety in three prospective studies. Cognitive Therapy
\& Research, 28, 309-345. https://doi.org/10.1023/ B:COTR.0000031805.60529.0d

lacobucci, D. (2010). Structural equations modeling: Fit indices, sample size, and advanced topics. Journal of Consumer Psychology, 20, 90-98. https:// doi.org/10.1016/j.jcps.2009.09.003

Krepula, K., Bidzinska-Speichert, B., Lenarcik, A., \& Tworowska-Bardzinska, U. (2012). Quality of life and the frequency of anxiety and depression in women with PCOS. Presented et 15th International \& 14th European Congress of Endocrinology. Endocrine Abstracts, 29, P948.

Mairet, K., Boag, S., \& Warburton, W. (2014). How Important is temperament? The relationship between coping styles, early maladaptive schemas and social anxiety. International Journal of Psychology \& Psychological Therapy, 14, 171-190.

Oettingen, J., Chodkiewicz, J., Mącik, D., \& Gruszczyńska, E. (2018). Polish adaptation of the Young Schema Questionnaire 3 short form (YSQ-S3-PL). Psychiatria Polska, 52, 707-718. https://doi.org/10.12740/ PP/OnlineFirst/76541

Oleś, P., Brygoła, E., \& Sibińska, M. (2010). Temporal dialogues and their influence on affective states and the meaning of life. International Journal for Dialogical Science, 4, 23-43.

Padesky, C. A., \& Greenberger, D. (1995). Clinicians guide to mind over mood. New York, NY: Guilford.

Siuta, J. (2006). Inwentarz Osobowości NEO-PI-R Paula T. Costy i Roberta R. McCrae. Adaptacja polska. Podręcznik [The Personality Inventory NEO-PI-R by Paul T. Costa and Robert R. McCrae. Polish adaptation. Manual]. Warszawa: Pracownia Testów Psychologicznych PTP.

Siuta, J. (Ed.) (2009). Diagnoza osobowości. Inwentarz NEO-PI-R w teorii i praktyce [Personality diagnosis. NEO-PI-R inventory in theory and practice]. Warszawa: Pracownia Testów Psychologicznych PTP.

Spielberger, C. D., \& Reheiser, E. C. (2003). Measuring anxiety, anger, depression, and curiosity as emotional states and personality traits with the STAI, STAXI, and STPI. In M. Hersen, M. J. Hilsenroth, \& D. L. Segal (Eds.), Comprehensive Handbook of psychological assessment (Vol. 2, pp. 70-86). Hoboken, NY: John Wiley \& Sons.

Spielberger, C. D., \& Reheiser, E. C. (2009). Assessment of emotions: Anxiety, anger, depression, and curiosity. Applied Psychology: Health and WellBeing, 1, 271-302. https://doi.org/10.1111/j.17580854.2009.01017.x

Stefanaki, C., Bacopoulou, F., Livadas, S., Kandaraki, A., Karachalios, A., Chrousos, G. P., \& Diamanti-Kandarakis, E. (2014). Impact of a mindfulness stress management program on stress, anxiety, depression and quality of life in women with polycystic ovary syndrome: A randomized controlled trial. Stress, 18, 57-66. https://doi.org/10.3109/10253890.2014.974030 
Thimm, J. C. (2010). Personality and early maladaptive schemas: a five-factor model perspective. Journal of Behavior Therapy And Experimental Psychiatry, 41, 373-380. https://doi.org/10.1016/j.jbtep.2010.03.009

Weinstock, L. M., \& Whisman, M. A. (2006). Neuroticism as a common feature of the depressive and anxiety disorders: A test of the revised integrative hierarchical model in a national sample. Journal of Abnormal Psychology, 115, 68-74. https://doi. org/10.1037/0021-843X.115.1.68

Wells, A. (1997). Cognitive therapy of anxiety disorders: A practice manual and conceptual guide. Hoboken, NJ: John Wiley \& Sons Inc.

Young, J. E., Klosko, J. S., \& Weishaar, M. E. (2003). Schema therapy: A practitioner's guide. New York, NY: Guilford Press.

Zawadzki, B., Strelau, J., Szczepaniak, P., \& Śliwińska, M. (1998). Inwentarz osobowości NEO-FFI Costy i McCrae. Adaptacja polska [Personality Inventory NEO-FFI Costa \& McCrae. Polish adaptation]. Warszawa: Pracownia Testów Psychologicznych PTP. 